\title{
Drawbacks and Limitations of Black-Scholes Model for Options Pricing
}

\author{
Zuzana Janková \\ Brno University of Technology, Faculty of Business and Management, \\ Institute of Informatics, Czech Republic \\ xpjanko01@vutbr.cz
}

Received date: 30 January 2018; Accepted date: 06 April 2018; published date: 10 August 2018.

Academic Editor: Mihail Busu

Copyright @ 2018. Zuzana Janková. Distributed under Creative Commons CC-BY 4.0

\begin{abstract}
The present paper focuses on the methods of derivative contract pricing. The basic differential equation of the popular Black-Scholes model for option contract pricing is derived. Furthermore, its less known modifications by Merton and Garman and Kohlhagen are pointed out. The paper refers to the significant drawbacks and limitations of the option pricing models that are based on constricting and unrealistic assumptions that often fail in comparison to the real market data. Attention is paid to the most serious problem, namely the issue of constant volatility, which is considerably disrupted in practice. Models implementing both stochastic and deterministic volatility in the original model are pointed out, their output being a more accurate option contract price.
\end{abstract}

Keywords: Differential equations, financial derivatives, Black-Scholes model, GARCH, volatility.

\section{Introduction}

Financial derivatives are becoming increasingly popular these days, not only as hedging instruments but they are also used more and more frequently for speculative transactions. For this reason, it is important not only for the general public to apply models allowing correct quantification of the exact prices of these financial derivatives. The gradual development of mathematical models enabled the spread of these instruments that improve the efficiency of the global financial market. A major part of the paper deals with the original BlackScholes model, which resulted in the expansion of option contract trading, mostly due to its simplicity and comprehensiveness.

Cite this Article as: Zuzana Janková (2018)," Drawbacks and Limitations of Black-Scholes Model for Options Pricing ", Journal of Financial Studies \& Research, Vol. 2018 (2018), Article ID 179814, 
In the context of the Black-Scholes model discrepancy with the real financial market development, two known modified models are introduced. The first one is the Merton model which, unlike the original model, also accounts for the underlying asset dividends, and the second one is the Garman-Kohlhagen model of currency option pricing. Other less known modern modified versions are introduced to give a picture of the current situation. The issues of volatility determination in the original model and the disruption of the constant volatility assumption are pointed out as well.

\section{Current Knowledge Status}

In their paper, Appleby and Riedle (2013) assume a stochastic differential equation model in an inefficient financial market, which is a generalisation of the Black-Scholes model, while the past stock price fluctuations affect future fluctuations. The same authors also show there are two different types of market behaviour, dependent on the attitudes and behaviours of investors. Similarly, Lee at al. (2013) create a model of basic asset prices in the form of stochastic delay differential equation in order to get an approximate price of a European-style option, based on the economic evidence showing that past underlying asset prices affect the future price. Li et al. (2014) examined the effects of delay on the stochastic resonance of the stock prices in the financial market with the Heston model driven by the extrinsic and intrinsic periodic information. Lin et al. (2018) discussed the pricing of European options on two underlying assets with delays whose price processes satisfy geometric Brownian motions with delays. Cordoni et al. (2017) discussed stochastic functional delay differential equation, whose evolution depends on its past history as well as on its present state. A different view of the valuation of financial derivatives by binomial tree methods is provided by Hyong-chol et al. (2016). Cordoni and Persio (2016) focused on financial models which take into account credit risk factors and generalized results by exploiting techniques developed to treat backward stochastic differential equations. Other authors who attempted to deal with the challenges represented by the limiting assumptions of the Black-Scholes model and thus to create their own modified models include Hull (2015), Ugbebor and Edeki (2013).

\section{Financial Derivative Valuation Models}

Presently, derivative contracts represent a large portion of the financial market and they are used mostly as a basic instrument for hedging various risks. The gradual development of mathematical models enabled the spread of these future instruments that improve the efficiency of the global financial market. The BlackScholes option valuation model has been very popular for several decades now and led to the boom in option trading, in particular because it is simple and understandable. Although the price of the option established based on this model almost corresponds to the real price, there are certain drawbacks that remain and are known and many researchers have been trying to eliminate them and to create a more suitable framework for valuation of financial derivatives. For this reason, there are plentiful modified mathematical models to be found in contemporary literature. Therefore, the following part of the paper discusses the standard Black-Scholes model and its two known versions, i.e. the Merton model and the Garman Kohlhagen model.

\section{Black-Scholes Model}

The Black-Scholes model (B-S) is a renowned pricing method originally created for the valuation of European option. The model was first derived and published in Journal of Political Economy under the title The Pricing of Options and Corporate Liabilities in 1973. Black, Scholes and later Merton constructed the model based on the assumption that an option can be perfectly replicated by purchase and sale of the basic instrument and a risk-free asset in a certain proportion, 
which eliminates the risk. In other words, the price of the option is implicitly determined by the development of the price of the underlying asset. Understanding the model and its correct function requires the assumptions the model is based on to be taken into account. The authors of the model consider ideal market conditions, such as that the short-term interest rate is known and constant in time, the option is European, there is no arbitrage, the underlying asset is a share without dividends, there are no transaction costs or taxes, etc.

The assumption of no arbitrage was crucial in deriving the Black-Scholes model. Let us mark the value of the call option at time $T$ as $C(S, X, T, r, \sigma)$, and let us note that $X$ expresses the strike price, 5 the spot rate, $r$ the risk-free constant interest rate and the share volatility is indicated by $a$. By partial derivation of the call option value based on the spot rate $S$ we obtain $\partial C / \partial S=\Delta_{C}$ delta call indicator that expresses the change in the call option value $C$, with the change of the spot rate of the underlying instruments.

The value of portfolio $V p$ consisting of the underlying share with rate $S$ and $1 / \Delta_{\mathcal{C}}$ of the sold call options equals $V p=5-1 / \Delta_{z} C(5, x, t, r, \sigma)=5-1 /(\partial C / O 5) C$ . Ambrož (2002) adds that with a slight change in $\boldsymbol{t}$ the value of underlying share 25 and the value of call option $\partial C$ change. The value of the portfolio as a whole change by analogy:

$\partial V p=\partial S-1 / \Delta_{C} \partial C=\partial S-1 /(\partial C / \partial S) \partial C$.

However, the risk-free nature of the portfolio needs to be taken into account as it is hedged by the call option. If the value of the portfolio changes in time $\partial t$, this change must be the same as with the risk-free asset.

\section{Merton Model}

The Merton model was published not long after the Black-Scholes model. An essential difference between the two models is constituted by the fact that Merton's model also accounts for dividends, which are not included in the former model. Nevertheless, this model has not become as popular as the former one, in particular due to the fact that it operates with a continuous dividend paid in the same amount. The above restricting assumption makes the model considerably unrealistic; however, later it turned out that regardless of the restriction, it is suitable e.g. for valuating futures and currency options, etc.

\section{Garman Kohlhagen Model}

In 1983 Garman and Kohlhagen published their article titled Foreign Currency Option Value in the Journal of International Money and Finance, in which they modified the original Black-Scholes model of currency option valuation that originally assumes a domestic interest rate only. A currency option established the right to buy or sell a fixed amount of a foreign currency for a previously set price at a previously set time. A currency option, similar to another derivative, may be used as an instrument of investment and hedging. It is one of the best instruments both for corporations and individuals to avoid adverse exchange rate fluctuations. (Ambrož, 2002)

\section{Drawbacks and Limitations of These Models}

Confrontation of the model assumptions with the real world assumptions is a necessary step. The Black-Scholes model is based on the above derived differential equation that models the price process of the underlying asset of a given option. It is obvious at first sight that the simplifying characteristics implied by these assumptions, such as a continuous process or normal distribution, often fail when compared to the real market data. Embrechts et al. (1999) state that the financial data show a tendency to noncontinuous to jump-like progress.

The theory and examination of differential equations, in particular partial equations, has become a popular subject for studying 
potential price problems, mainly after the classic Black-Scholes model was designed. In the last two decades, researchers have been more and more interested in the B-S equation as it is a very effective and simple instrument for option valuation. Yet it does not change the fact that the original version was created under certain strict assumptions that are often not valid in reality. For this reason, a large number of models have been designed, attempting to improve the original model and remove its drawbacks and extend some of the conditions in order for them to reflect the real market development more accurately.

Before the model derivation, it was pointed out that the non-existence of arbitrage is a crucial prerequisite leading to the differential equation solved by the Black-Scholes formula. However, in practice, as stated by Ambrož (2002), this is violated and often results in anomalies. Another strong prerequisite necessary for the derivation of the Black-Scholes model is the perfect derivative replication by the share and a riskfree instrument; however, this cannot be achieved without transaction costs. Grossman and Zhou (1996) found that volatility correlates not only to the share price but also to the volume of trade and transaction costs. As a result, new models reflecting transaction costs have been created, e.g. by Davis et al. (1993) or Taksar et al. (1998) as well as models proposing modification of the original model by volatility that is not constant, such as Hull and White (1987). Since investors tend to monitor the historical development of prices of the instruments before they decide to invest, Arriojas et al. (2007) and Kazmerchuk et al. (2007) assume that the modelling of the real development can be improved by volatility dependent on the history of stock prices. Stock prices are influenced by certain previous events that took place prior to the start of the trading. Moreover, the original model does not account for the payment of dividends for the underlying share, yet the majority of stock corporations pay dividends. Thus, according to Pavlát (1994), option holders are at a significant disadvantage compared to shareholders. This problem has been solved by Merton's model that gained its status among the investor public. It is obvious that if $\mathrm{q}$ is constant and volatility is not affected in any way, Merton's model is automatically reduced to the original BlackScholes model. Ekvall et al. (1997) reviewed the G-K model. According to the authors, this model is not very satisfactory, as it is based on the B-S model, which is constructed mainly for share options and not for currencies that behave differently and this needs to be respected and not overlooked. Kung (2013) considers the original G-K model to be unsuitable as both spot rates are not constant, but in reality they develop continuously and stochastically over time. And he has included the stochastic character in his model using the Wiener process.

\section{Problem of Volatility}

The volatility of underlying asset returns is definitely the most critical and most widely discussed parameter of the Black-Scholes model. The analysed pricing models assume, among other requirements, constant volatility; in other words, they expect constant underlying asset returns. The underlying asset volatility is expressed by the range $a^{2}$, or standard deviation $\sigma$. A high parameter value indicates considerably more significant price fluctuation as well as a higher degree of uncertainty of achieving the desired return. Volatility determination is absolutely crucial for correct option contract pricing. Volatility may basically be estimated based on the history of the underlying asset returns or based on the option contract price (implied volatility). The advantage of implied volatility is that it uses current market data instead of historical data. Volatility can be determined based on the volatility attributed to the share of a correctly priced option. Subsequently, this volatility can also be used as a parameter of the Black-Scholes model for the option to be priced. Nevertheless, in all the above cases, volatility is constant since it is expressed by a single value characteristic for a given underlying asset. 
The simplest method of volatility calculation uses the historical prices, namely the selection range of logarithmic increase of the underlying asset prices of a given option. However, Černý (2008) refers to the fact in the context of historical volatility that the situation in the past may be significantly different from the present as the previous period may include e.g. a financial crisis, burst of a speculative bubble, etc.

Volatility can be predicted using the GARCH model (generalized autoregressive conditional heteroskedasticity). In the model, the time series are characterized by changes in conditional variance when a period of high volatility is followed by a period of minor fluctuations. The model gives the information that tomorrow's volatility depends on today's volatility value and today's new financial market information. The study of asset price models within the GARCH processes is a new derivative instrument approach. Duan (1992) was the first to provide solid theoretical option contract framework. The GARCH model was also tested by Sheraz and Preda (2013) who continue the model of Gonga et al. (2010b).

Soukal (2003) adds that volatility can basically be divided to constant, see above and non-constant, which can have a deterministic or stochastic character. Empirical studies have shown that the constant volatility assumption is not true. Applying the Black-Scholes model to the option market price with the same expiry period with different strike prices will create a graph referred to as the volatility smile, according to the $U$ shape it often manifests. Hull (2009) notes that if the implied volatility is expressed as a function of two variables $\sigma_{\text {ims }}=\sigma_{\text {lmo }}((B, \tau)$, namely the strike price and time to maturity, the resulting graph is referred to as volatility surface. It can be stated that the smile curve is more stable as it expresses dependency on the strike price, whereas the surface graph is much more variable. The empirical evidence of nonconstant volatility resulted in models that aim to implement the knowledge gained by empirical observations in the process, e.g. the change of constant volatility for deterministic or stochastic. Stochastic volatility was used in the studies of Gong et al. (2010a) using return data estimate the mean and variance of the stochastic volatility of the BlackScholes model. Hestona and Nandi (2000) question the GARCH model as according to the authors it is more suitable to use alternative models that allow for depicting the asymmetry of the shocks in volatility and are inclined to stochastic volatility.

\section{Conclusion}

The presented paper focuses on models of financial derivative pricing. In particular, the famous Black and Scholes model for the determination of option contract prices is derived, which is still widely used by the general investor public, regardless of its considerably limiting and constricting assumptions. A modified version of the original Black-Scholes model has been presented by Merton who eliminated the drawback of absence of dividend payments from the underlying share. Garman and Kohlhagen reviewed the model as well and focused on the valuation of currency options while using both domestic and foreign interest rates. Nevertheless, all the models work with constant volatility, while the volatility is non-constant as shown by many empirical studies, in particular in turbulent times when the economy deviates from standard conditions. For this reason, attention is paid mostly to this most important assumption.

It is a well-known fact that the correct volatility estimate is probably the most serious problem in option pricing using the Black-Scholes model, since every percentage point usually has a huge value. This is not the only reason why a whole range of modifications have been created in the attempt to remove the drawbacks of the original Black-Scholes model and to revise it by including non-constant volatility, either deterministic or stochastic, with a more 
accurate option contract price being the output. Nevertheless, so far there has not been a universally applicable form. However, it should be noted that certain limiting factors can be viewed as insignificant; therefore the original Black-Scholes formula can be regarded as a universal pricing model giving approximately correct theoretical option contract prices.

\section{Acknowledgements}

The author would like to thank, for the support of the Institute of Informatics, Faculty of Business and Management of the Brno University of Technology, doc. RNDr. Bedřich Půža, Csc. and Mgr. Veronika Novotná, Ph.D during preparation of the paper. The paper is an output of the specific research project: "Information and Knowledge management in the 4.0 Industry" of the Internal Grant Agency of the Brno University of Technology, registration No. FP-S-18-5524.

\section{References}

1. Ambrož, L. (2002) Oceňování opcí. Praha: C.H. Beck.

2. Appleby, JAD., Riedle. M. and Swords, C. (2013), 'Bubbles and crashes in a BlackScholes model with delay,' Finance and Stochastics, 17(1), 1-30.

3. Arriojas, M. et al. (2007), 'A Delayed Black and Scholes Formula,' Stochastic Analysis and Applications, 25(2), pp.471-492.

4. Black, F. and Scholes MS. (1973), 'The Pricing of Options and Corporate Liabilities,' Journal of Political Economy, 81(3), 637-654.

5. Cerný, M. (2008), 'K odhadu volatility finančních řad při oceňování derivátů', Acta Oeconomica Pragensia, roč. 16, č. 4.

6. Cordoni, F. and Di Persio, L. (2016), 'A BSDE with Delayed Generator Approach to Pricing under Counterparty Risk and
Collateralization,' International Journal of Stochastic Analysis, 2016, pp.1-11.

7. Cordoni, F., Di Persio, L. and Oliva, I. (2017), 'A nonlinear Kolmogorov equation for stochastic functional delay differential equations with jumps,' Nonlinear Differential Equations and Applications NoDEA, 24(2).

8. Davis, MHA. and Panas, V.G. (1991), 'European option pricing with transactions costs,' Proceedings of the 30th IEEE Conference on Decision and Control, pp.12991304.

9. Duan, J.C. (1992), 'The GARCH Option Pricing Model.' Mathematical Finance 5,p.332

10. Dvořák, P. (2008) Deriváty Vyd. 2., přeprac., V Praze, Oeconomica.

11. Ekvall, N., Jennergren, PL. and Näslund, B. (1997), 'Currency option pricing with mean reversion and uncovered interest parity: A revision of the Garman-Kohlhagen model,' European Journal of Operational Research, 100(1), pp.41-59.

12.Embrechts, P, Klüppelberg, C., Mikosch, T. (1999), 'Modelling External Events', SpringVerlag, Berlin, vol. 5, issue 02, 465-465.

13.Gong, H., Thavaneswaran, A. \& Singh, J. (2010a), 'Stochastic Volatility Models with Application in Option Pricing.' Journal of Statistical Theory and Practice, 4(4), pp.541557.

14. Gong, H., Thavaneswaran, A., Sing, J. (2010b), 'A Black-Scholes Model with GARCH Volatility.' The Mathematical Scientist, 35,p. 37-42.

15.Grossman, S. J. and Zhou, Z. (1996), 'Equilibrium Analysis of Portfolio Insurance,' The Journal of Finance, 51(4), pp.1379-1403.

16. Heston, S. L., Nandi, S. (2000), 'A ClosedForm GARCH Option Valuation Model.' The Review of Financial Studies, Vo. 13, No. 3. 
17. Hull, J. (2015) Options, futures, and other derivatives Ninth edition., Boston: Pearson.

18. Hull, J. (2009) Options, futures and other derivatives 7th ed., Upper Saddle River, N.J: Pearson Prentice Hall.

19. Hull, J. and White, A. (1987), 'The Pricing of Options on Assets with Stochastic Volatilities,' The Journal of Finance, 42(2), pp.281-300.

20.Hyong-Chol O., Kim M.C., Kim GR. (2016), 'Convergence of binomial tree method and explicit difference scheme for American put options with time dependent coefficients, ' Quant. Finance, 16 (2), pp. 1271-1277.

21. Kazmerchuk, Y., Swishchuk, A. and Wu, J. (2007), 'The pricing of options for securities markets with delayed response.' Mathematics and Computers in Simulation, 75(3-4), pp.6979.

22. Kohout, P. (2013), Investiční strategie pro třetí tisíciletí 7., aktualiz. a přeprac. vyd., Praha: Grada.

23. Kung, JJ. (2013), 'A Continuous-Time Model for Valuing Foreign Exchange Options,' Abstract and Applied Analysis, 2013, pp.1-10.

24. Lee, C F., Lee, J C. and. Lee, A C. (2013) Statistics for business and financial economics 3rd ed., New York, NY: Springer.

25. Lee, M K., Kim, J H. and Kim, J. (2011), 'A delay financial model with stochastic volatility; martingale method,' Physica A: Statistical Mechanics and its Applications, 390(16), pp.2909-2919.

26. Li, J Ch., Li, Ch. and Mei, D Ch. (2014), 'Effects of time delay on stochastic resonance of the stock prices in financial system,' Physics Letters A, 378(30-31).

27.Lin, L., Li, Y. and $\mathrm{Wu}, \mathrm{J}$. (2018), 'The pricing of European options on two underlying assets with delays,' Physica A:
Statistical Mechanics and its Applications, 495, pp.143-151.

28. Merton, R. (1976), 'Option pricing when underlying stock returns are discontinuous,' Journal of Financial Economics, 3 (1-2), 125144.

29. Oaikhenan, H. and Osunde, O. (2006), 'Financial derivatives: empirical analysis of factors that affect the demand for rights (derivatives) in the nigerian stock market,' Journal of Financial Management \& Analysis, Mumbai: Om Sai Ram Centre for Financial Research, 19(1), 36-44.

30. Pavlát, V. (1994) Finanční opce, Praha: Magnet-Press.

31.Polách, J. (2012) Reálné a finanční investice, V Praze: C.H. Beck.

32. Polouček, S. (2009) Peníze, banky, finanční trhy, V Praze: C.H. Beck.

33. Sheraz, M. \& Preda, V. (2014), 'Implied Volatility in Black-scholes Model with Garch Volatility. ' Procedia Economics and Finance, 8, pp.658-663.

34.Soukal, P. (2003), 'Empirické ověření Black-Scholesova modelu oceňování opci na akcie General Electric a IBM", diplomová práce, Praha, VŠE.

35. Taksar, M., Klass, MJ. and Assaf, D. (1988), 'A Diffusion Model for Optimal Portfolio Selection in the Presence of Brokerage Fees,' Mathematics of Operations Research, 13(2), pp.277-294.

36.Ugbebor, 00., Edeki, SO. (2013), 'On Duality Principle in Exponentially Le'vy Market,' J. Appl. Math. Bioinform, 3, 159-170. 